\title{
BMJ Prevalence, awareness, treatment and Open control of hypertension in a self- selected sub-Saharan African urban population: a cross-sectional study
}

\author{
Anastase Dzudie, ${ }^{1,2}$ André Pascal Kengne, ${ }^{3}$ Walinjom F T Muna, ${ }^{4,5}$ Hamadou Ba, ${ }^{5}$ \\ Alain Menanga, ${ }^{4,5}$ Charles Kouam Kouam, ${ }^{6}$ Joseph Abah, ${ }^{7}$ Yves Monkam, ${ }^{1}$ \\ Christian Biholong, ${ }^{1}$ Pierre Mintom, ${ }^{5}$ Félicité Kamdem, ${ }^{1}$ Armel Djomou, ${ }^{1}$ \\ Jules Ndjebet, ${ }^{1}$ Cyrille Wambo, ${ }^{1}$ Henry Luma, ${ }^{1}$ Kathleen Blackett Ngu, ${ }^{8}$ \\ Samuel Kingue, ${ }^{4,5}$ On behalf of the CCS investigator group ${ }^{i}$
}

To cite: Dzudie A,

Kengne AP, Muna WFT, et al. Prevalence, awareness, treatment and control of hypertension in a selfselected sub-Saharan African urban population: a crosssectional study. BMJ Open 2012;0:e001217. doi:10.1136/bmjopen-2012001217

- Prepublication history and additional material for this paper are available online. To view these files please visit the journal online (http:// dx.doi.org/10.1136/bmjopen2012-001217).

For author footnote see end of the article.

Received 1 April 2012 Accepted 23 July 2012

This final article is available for use under the terms of the Creative Commons Attribution Non-Commercial 2.0 Licence; see http://bmjopen.bmj.com

For numbered affiliations see end of article

\section{Correspondence to} Dr Anastase Dzudie; aitdzudie@yahoo.com

\section{ABSTRACT}

Objectives: Hypertension has been established as a major public health problem in Africa, but its specific contributions to disease burden are still incompletely understood. We report the prevalence and determinants of hypertension, detection, treatment and control rates among adults in major cities in Cameroon.

Design: Cross-sectional study.

Settings: Community-based multicentre study in major cities in Cameroon.

Participants: Participants were self-selected urban dwellers from the Center, Littoral, North-West and West Regions, who attended on 17 May 2011 a screening campaign advertised through mass media.

Primary and secondary outcomes measures: Hypertension defined as systolic (and/or diastolic) blood pressure (BP) $\geq 140(90) \mathrm{mm} \mathrm{Hg}$, or ongoing BPlowering medications.

Results: In all, 2120 participants (1003 women) were included. Among them, 1007 (prevalence rate 47.5\%) had hypertension, including 319 (awareness rate $31.7 \%$ ) who were aware of their status. The prevalence of hypertension increased with age overall and by sex and region. Among aware hypertensive participants, 191 (treatment rate 59.9\%) were on regular BP-lowering medication, and among those treated, 47 (controlled rate $24.6 \%$ ) were at target BP levels (ie, systolic (and diastolic) $\mathrm{BP}<140(90) \mathrm{mm} \mathrm{Hg}$ ). In multivariable logistic regression analysis, male gender, advanced age, parental history of hypertension, diabetes mellitus, elevated waist and elevated body mass index (BMI) were the significant predictors of hypertension. Likewise, male gender, high BMI and physical inactivity were associated with poor control.

Conclusions: High prevalence of hypertension with low awareness, treatment and control were found in this urban population; these findings are significant and alarming with consideration to the various improvements in the access to healthcare and the continuing efforts to educate communities over the last few decades.

\section{ARTICLE SUMMARY}

Article focus

- This article quantified the burden and determinants of hypertension, detection, treatment and control rates among self-selected adults in major cities in Cameroon, central Africa.

Key messages

- The prevalence of hypertension was very high in this population, coupled with low detection, treatment and control rates.

- Age, gender and excess weight were the main drivers of the high prevalence, while the coincidence of classical cardiovascular risk factors was associated with poor control.

Strengths and limitations of this study

- Major strengths of this study include the large sample, the multicenter nature, the rigorous data collection on a range of determinants and provision of standardised prevalence figures.

- Limitations include the selection of participants, and hypertension diagnosis based on blood pressure measurement during a single encounter.

\section{INTRODUCTION}

Hypertension has been established as a major public health problem worldwide. ${ }^{1}$ Several published studies suggest that hypertension is the commonest modifiable risk factor for stroke, congestive heart failure and kidney failure ${ }^{2-5}$ in the sub-Saharan African (SSA) region. It is a major contributor to overall death risk in adults in the region. ${ }^{6}$ Hypertension also seems to be more common in urban than rural population ${ }^{7}$ of the SSA region. 
Specific risks associated with various blood pressure (BP) readings have largely been established for populations in many parts of the developed world but this is not the case for countries of the developing world including the SSA region. There is considerable evidence that long-term BP lowering to what is considered either normal or optimal levels results in several significant and important health benefits. ${ }^{8}$ When established norms for ideal or optimal BP are applied to SSA populations, it becomes very evident that the vast majority of eligible patients do not enjoy the benefits of BP-lowering therapies, either because of under-diagnosis or the many other barriers to BP-lowering medications prescription, access and compliance in this setting. ${ }^{12}$ As a case-in point, a survey in Cameroon about 8 years ago found that only $23 \%$ of all individuals with hypertension at the community level were aware of their status. ${ }^{9}$ Moreover, only $46 \%$ of those aware $(11 \%$ of all those with hypertension) were on treatment, among whom only $19 \%$ (2\% of all those with hypertension) achieved expected target BP levels. ${ }^{9}$

There is also evidence that SSA is undergoing very rapid transitions characterised by increasing urbanisation, including the adoption of unhealthy lifestyles. ${ }^{10} 11$ These transitions are paralleled by changes in the profile of chronic disease risk factors including BP. ${ }^{7}$ Recently, there has been increasing awareness of the threat that the looming chronic diseases pose to the health of the population in the Region at different levels. ${ }^{12}$ This increasing awareness has catalysed initiatives aimed at improving access to detection and care of chronic diseases including hypertension ${ }^{13}$ in many countries of the region. The pace of the above mutations suggests that data on the burden of hypertension must be updated regularly, in order to provide the reliability needed in drawing-up health service and policy solutions.

The aim of this study was to assess the prevalence and determinants of hypertension, and including the detection, treatment and control rates, as well as the variability by region and gender in four major cities of Cameroon.

\section{MATERIAL AND METHODS}

\section{Study population and settings}

This was a cross-sectional population-based study conducted in the regional capitals of the Centre (Yaounde), Littoral (Douala), North-West (Bamenda) and West (Bafoussam) administrative regions (out of a total of 10) of Cameroon. According to the Cameroon National Institute of Statistics, ${ }^{14}$ the four participating regions had a total population of 9.98 million in 2010 (51\% of the country's total population: 19.41 millions). In the same year, $57.5 \%$ of the national population was aged 15 years and above, and about $52 \%$ resided in what was defined as an urban area. ${ }^{14}$ During three consecutive weeks leading to the specified day of the survey, daily announcements were made through radio and television, inviting all interested adults (or individuals aged 15 years and above) to report to any of the screening sites in participating cities. Such explanation included advice on the importance of measuring and knowing one's BP under the slogan 'I know my BP. And you?'. Announcements were also made in churches and market places. The study protocol was approved by the Cameroon National Ethics Committee and signed informed consent was obtained from each participant.

\section{Data collection}

The screening was conducted by trained medical personnel, simultaneously in the four cities on the specified date of 17 May 2011. All participants were subjected to a face-to-face interview during which data were collected (using a standardised questionnaire) on demographics, smoking habits and alcohol consumption, physical activity, parental history of hypertension, personal medical history (where the diagnosis was made by a physician) of hypertension including drug treatment, diabetes mellitus, gout and dyslipidaemia. The physical examination included BP and anthropometric measurements. BP (systolic and diastolic) was measured using a standardised protocol with the participant in a seated position, and after at least $10 \mathrm{~min}$ rest. Participants with evidence of recent (less than $30 \mathrm{~min}$ ) alcohol intake or smoking were invited to a $30 \mathrm{~min}$ rest before $\mathrm{BP}$ measurement. BP measurements were performed on the right arm using automated sphygmomanometers (OMRON M3 HEM-7200-E Omron Matsusaka Co Ltd, Kyoto, Japan). Special attention was given to the use of appropriate cuff sizes $(13 \times 23 \mathrm{~cm}$ or $16 \times 30 \mathrm{~cm})$. Weight (to the nearest $0.5 \mathrm{~kg}$ ) was measured with the use of an automated scale. Participants were permitted to keep on light clothing. Height (in metres to the nearest $0.5 \mathrm{~cm}$ ) was measured using a wooden platform and a height rule. Body mass index $\left(\mathrm{BMI}\right.$ in $\left.\mathrm{kg} / \mathrm{m}^{2}\right)$ was calculated as weight $(\mathrm{kg}) /($ height $(\mathrm{m}) \times$ height $(\mathrm{m}))$. Waist circumference was measured midway between the iliac crest and the lower rib margin and the hip circumference was measured at the intertrochanteric level. Waist-to-hip ratio (WHR) was calculated as waist $(\mathrm{cm}) / \mathrm{hip}(\mathrm{cm})$ circumferences.

\section{Definitions}

Respondents were classified as hypertensive if they had a systolic (and/or diastolic) BP of 140 (90) $\mathrm{mm} \mathrm{Hg}$ or higher, or if they were on BP-lowering medications over the last 15 consecutive days. Participants with hypertension were considered to be aware of their status if they answered 'yes' to the question 'Have you ever been told by a doctor or health professional that you had hypertension?'. Treatment of high BP was defined by the use of BP-lowering medications. Hypertension was considered to be controlled among treated individuals when systolic (and diastolic) SBP was $<140$ (90) $\mathrm{mm} \mathrm{Hg}$ or $<130$ (80) $\mathrm{mm} \mathrm{Hg}$ in individuals with diabetes. Waist 
circumference $>94 \mathrm{~cm}$ in men or $80 \mathrm{~cm}$ in women was considered to be high. Excessive alcohol consumption was based on intake of either more than 3 (2 for women) standard glasses of wine per day or more than 10 (5 for women) local beers (1 local beer contains $28 \mathrm{~g}$ of alcohol) per week. Traditional alcohol beverages were not assessed. Participants who smoked at least one cigarette per day at the time of the study were classified as current smokers, and those who have smoked for at least 3 years in the past, but had stopped by the time of the study, were classified as former smokers. Regular non-work-related physical activity was considered in participants reporting at least $30 \mathrm{~min}$ of intense physical activity, once a week or more.

\section{Handling of participants with high BP}

Participants with hypertension (known or screeneddetected) received on-site medical counseling and were referred back to their attending physician (known cases), or to specialists within the vicinity of the participant's residential area for workup and long-term management. Few participants with excessively high BP with or without suspected acute target organ damage were immediately referred to emergency departments for appropriate care.

\section{Statistical analysis}

Data analysis used the Statistical Package for Social Sciences (SSPS Inc, Chicago, Illinois, USA) V.17.0 software. Results are summarised as count and percentages for qualitative variables and mean and SD for quantitative variables. Age-adjusted prevalence was calculated using the Cameroon National population's age structure in 2010 as standard population. ${ }^{15}$ Direct standardisation methods was applied. ${ }^{16}$ Group comparisons used $\chi^{2}$ tests and equivalents for qualitative variables and student $\mathrm{t}$ test, analysis of the variance for quantitative variables. Logistic regression analyses were used to investigate potential determinants of prevalent hypertension and control. A $p$ value $<0.05$ was used to characterise statistically significant results.

\section{Sensitivity analysis}

The main analyses were based on a single BP measurement. To assess the potential effects of 'regression to the mean' phenomenon on the prevalence of hypertension, a sensitivity analysis was conducted among participants with a raised initial $\mathrm{BP}(\mathrm{SBP} / \mathrm{DBP} \geq 140 / 80 \mathrm{~mm} \mathrm{Hg})$ and who had their BP taken a second time on the same day. This analysis was based on the average of the first and second measurements.

\section{RESULTS}

\section{Study population}

About 2120 eligible participants reported for screening in the four regions including $649(30.6 \%)$ in the Centre, $1167(54.1 \%)$ in the Littoral and $304(14.3 \%)$ in the
West and North West regions. Their overall profile including gender and region is summarised in table 1 . Participants included 1003 women (47.3\%). Compared with men, women had similar age (43 vs 44 years, $\mathrm{p}=0.19$ ), similar waist circumference (93 vs $93 \mathrm{~cm}$, $\mathrm{p}=0.80$ ) and similar history of diabetes mellitus, dyslipidaemia and gout (all $\mathrm{p} \geq 0.07$, table 1 ). They were likely to have higher BMI, higher prevalence of parental history of hypertension, lower systolic and diastolic BP, and were less likely to be either a smoker or alcohol drinker and physically active (all $p \leq 0.001$, table 1 ). With a few exceptions, the above pattern was consistent within participating regions. However, the small number of recruits in some subgroups translated into nonsignificant men/women differences (table 1). With the exception of smoking $(\mathrm{p}=0.07)$, differences were also apparent in the baseline profile across Regions (all $\mathrm{p} \leq 0.01$ for differences across regions; table 1 ).

\section{BP profile}

Mean systolic and diastolic BP (SD) at the total population level (men vs women) was 139 (25) vs 134 (28) $\mathrm{mm} \mathrm{Hg} \quad(\mathrm{p}<0.001)$, and 83 (17) vs 80 (17) $\mathrm{mm} \mathrm{Hg}$ $(\mathrm{p}=0.001)$. Mean systolic BP steadily increased with increasing age in men and women and across participating regions. Diastolic BP also increased with increasing age, but only up to the fourth and fifth decade of age, after which the pressure stabilised. This was observed in men and women and across regions (figure 1).

The distribution of participants by BP categories according to the $2003 \mathrm{ESH} / \mathrm{ESC}$ classification ${ }^{17}$ was examined by sex and regions, overall and by age groups. An optimal BP (systolic $\mathrm{BP}<120$ and diastolic $\mathrm{BP}<80 \mathrm{~mm} \mathrm{Hg}$ ) was observed in $21.6 \%$ of men and $29.6 \%$ of women. The prevalence of optimal or normal $\mathrm{BP}$ decreased with increasing age in men and women (all $\mathrm{p} \leq 0.001$ for linear trend). Conversely, with the exception of grade 1 hypertension (both $\mathrm{p} \geq 0.09$ for linearity) and high normal BP in women only $(\mathrm{p}=0.13)$, the prevalence of all other BP categories linearly increased with increasing age (all $\mathrm{p}<0.001$ for linear trend). Similar trends were also observed across participating regions. However, the distribution of participants across BP categories varied significantly by region $(\mathrm{p}<0.0001)$.

\section{Prevalence of hypertension and awareness and control rates}

The prevalence of hypertension was $47.5 \%$ overall, and $50.1 \%$ and $44.6 \%$ in men and women, respectively ( $\mathrm{p}<0.001$, table 2$)$. As expected, prevalence rate sharply increased with age down from $31.7 \%$ (men) and $20.2 \%$ (women) in the age group <35 years, up to $77.6 \%$ (men) and $75.2 \%$ (women) in the age group 55 years and above (table 2). Awareness rate increased with increasing age in men and women (both $\mathrm{p}<0.001$ for linear trend). Among participants with hypertension, $24.6 \%$ in men and $40.5 \%$ in women were aware of their condition, and those remaining were newly diagnosed. 


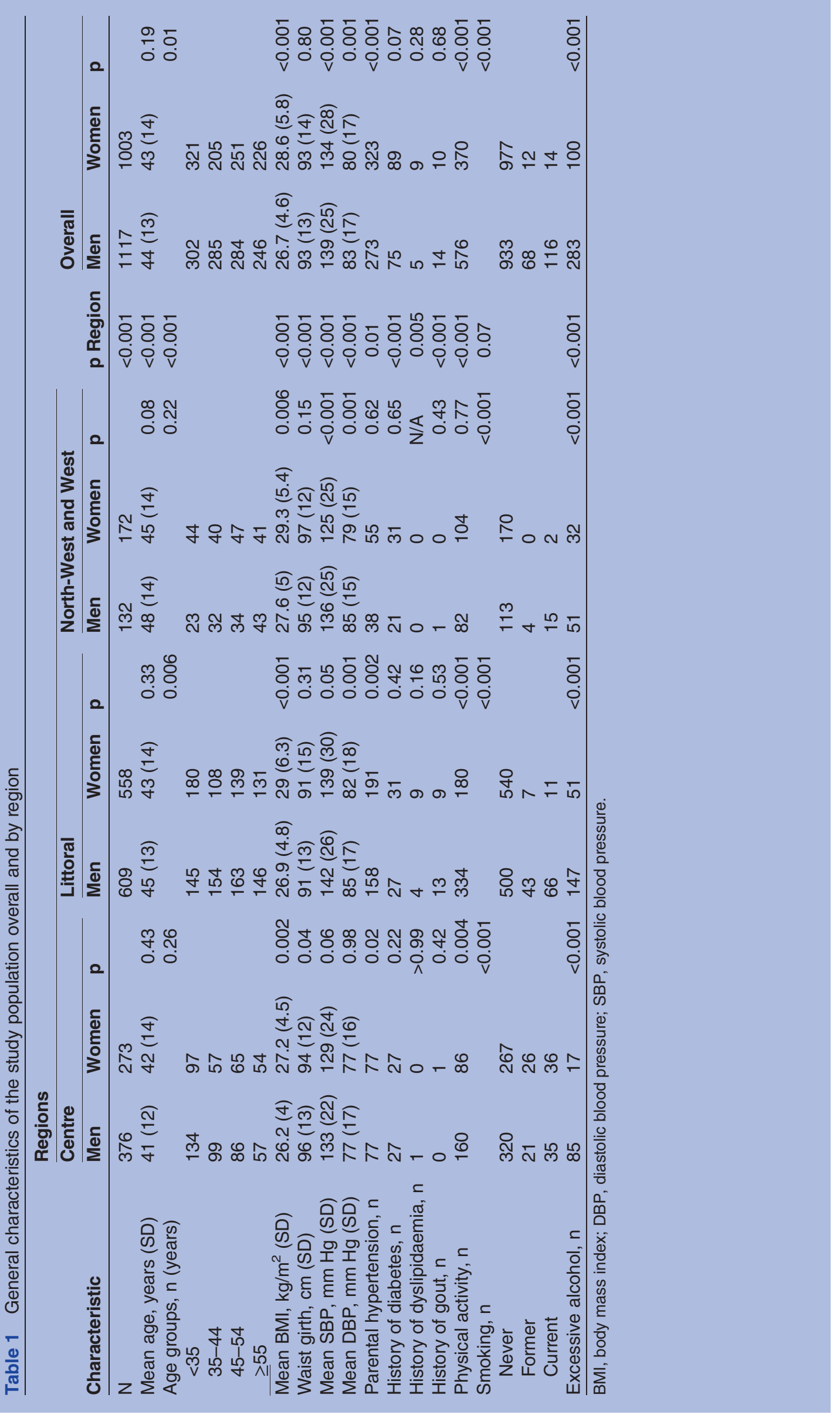


Table 2 Hypertension prevalence, awareness and control among self-selected urban dwellers in Cameroon

\begin{tabular}{|c|c|c|c|c|c|c|c|c|}
\hline \multirow{2}{*}{$\begin{array}{l}\text { Gender } \\
\text { region }\end{array}$} & \multirow[b]{2}{*}{ Variable } & \multirow[b]{2}{*}{ Overall } & \multirow[b]{2}{*}{ Overall* } & \multicolumn{4}{|c|}{ Age groups (years) } & \multirow[b]{2}{*}{ p Trend } \\
\hline & & & & $<35$ & $35-44$ & $45-54$ & $\geq 55$ & \\
\hline \multirow[t]{10}{*}{ Centre } & Prevalence (\%) & 35.4 & $27.3(23.3-31.3)$ & 15.1 & 28.2 & 48.3 & 70.3 & $<0.001$ \\
\hline & $\begin{array}{l}\mathrm{SBP} / \mathrm{DBP} \geq 140 / 90 \mathrm{~mm} \mathrm{Hg} \text { or } \\
\text { treatment }(\mathrm{n})\end{array}$ & 230 & 230 & 35 & 44 & 73 & 78 & \\
\hline & Awareness (\%) & 30.4 & $12.5(9.3-15.7)$ & 0 & 22.7 & 31.5 & 47.4 & $<0.001$ \\
\hline & Among hypertensives ( $\mathrm{n}$ ) & 70 & 70 & 0 & 10 & 23 & 37 & \\
\hline & Treatment (\%) & 61.4 & $21.9(13.6-30.2)$ & NA & 50 & 52.2 & 70.3 & 0.13 \\
\hline & Among aware hypertensives (n) & 43 & 43 & NA & 5 & 12 & 26 & \\
\hline & Control A (\%) & 25.6 & $6.7(2.5-10.9)$ & NA & 0 & 33.3 & 26.9 & 0.41 \\
\hline & Among treated hypertensive (n) & 11 & 11 & NA & 0 & 4 & 7 & \\
\hline & Control B (\%) & 25.6 & $6.7(2.5-10.9)$ & NA & 0 & 33.3 & 26.9 & 0.41 \\
\hline & Among treated hypertensive (n) & 11 & 11 & NA & 0 & 4 & 7 & \\
\hline \multirow[t]{10}{*}{ Littoral } & Prevalence (\%) & 53.6 & $43.6(39.2-48)$ & 33.8 & 45 & 61.7 & 76.2 & $<0.001$ \\
\hline & $\begin{array}{l}\mathrm{SBP} / \mathrm{DBP} \geq 140 / 90 \mathrm{~mm} \mathrm{Hg} \text { or } \\
\text { treatment }(\mathrm{n})\end{array}$ & 626 & 626 & 110 & 118 & 187 & 211 & \\
\hline & Awareness (\%) & 25.1 & $15.1(11.3-18.9)$ & 9.1 & 11.9 & 25.1 & 40.8 & $<0.001$ \\
\hline & Among hypertensives (n) & 157 & 157 & 10 & 14 & 47 & 86 & \\
\hline & Treatment (\%) & 49 & $38.7(16.7-60.7)$ & 30 & 57.1 & 46.8 & 51.2 & 0.42 \\
\hline & Among aware hypertensives (n) & 77 & 77 & 3 & 8 & 22 & 44 & \\
\hline & Control A (\%) & 18.2 & $26.8(-13.7$ to 67.3$)$ & 33.3 & 12.5 & 22.7 & 15.9 & 0.60 \\
\hline & Among treated hypertensive (n) & 14 & 14 & 1 & 1 & 5 & 7 & \\
\hline & Control B (\%) & 18.2 & $26.8(-13.7$ to 67.3$)$ & 33.3 & 12.5 & 22.7 & 15.9 & 0.60 \\
\hline & Among treated hypertensive (n) & 14 & 14 & 1 & 1 & 5 & 7 & \\
\hline \multirow[t]{10}{*}{ Others } & Prevalence $(\%)$ & 49.7 & $34.4(26.6-42.2)$ & 22.4 & 30.6 & 51.8 & 85.7 & $<0.001$ \\
\hline & $\begin{array}{l}\mathrm{SBP} / \mathrm{DBP} \geq 140 / 90 \mathrm{~mm} \mathrm{Hg} \text { or } \\
\text { treatment }(n)\end{array}$ & 151 & 151 & 15 & 22 & 42 & 72 & \\
\hline & Awareness (\%) & 60.9 & $30.3(17.7-42.9)$ & 13.3 & 40.9 & 53.5 & 77.8 & $<0.001$ \\
\hline & Among hypertensives (n) & 92 & 92 & 2 & 9 & 25 & 56 & \\
\hline & Treatment (\%) & 77.7 & $91.6(5.6-178)$ & 100 & 77.8 & 84 & 73.2 & 0.30 \\
\hline & Among aware hypertensives & 71 & 71 & 2 & 7 & 21 & 41 & \\
\hline & Control A (\%) & 31 & $12.9(4.7-21.1)$ & 0 & 42.9 & 14.3 & 39 & 0.22 \\
\hline & Among treated hypertensive (n) & 22 & 22 & 0 & 3 & 3 & 16 & \\
\hline & Control B (\%) & 56.3 & $51.5(-9.7$ to 113$)$ & 50 & 57.1 & 33.3 & 68.3 & 0.12 \\
\hline & Among treated hypertensive (n) & 40 & 40 & 1 & 4 & 7 & 28 & \\
\hline \multirow[t]{10}{*}{ Men } & Prevalence (\%) & 50.1 & $41.3(36.9-45.7)$ & 31.7 & 38.9 & 57.2 & 77.6 & $<0.001$ \\
\hline & $\begin{array}{l}S B P / D B P \geq 140 / 90 \mathrm{~mm} \mathrm{Hg} \text { or } \\
\text { treatment }(n)\end{array}$ & 560 & 560 & 96 & 111 & 162 & 191 & \\
\hline & Awareness (\%) & 24.6 & $13.5(10-17)$ & 6.3 & 12.6 & 21.6 & 43.5 & $<0.001$ \\
\hline & Among hypertensives (n) & 138 & 138 & 6 & 14 & 35 & 83 & \\
\hline & Treatment $(\%)$ & 57.9 & $54.6(19.3-89.9)$ & 50 & 64.2 & 65.7 & 54.2 & 0.53 \\
\hline & Among aware hypertensives & 80 & 80 & 3 & 9 & 23 & 45 & \\
\hline & Control A (\%) & 18.8 & $28.2(-12$ to 68.6$)$ & 33.3 & 22.2 & 21.7 & 15.5 & 0.36 \\
\hline & Among treated hypertensive (n) & 15 & 15 & 1 & 2 & 5 & 7 & \\
\hline & Control B (\%) & 27.5 & $50.3(-6.3$ to 107$)$ & 66.6 & 22.2 & 26.1 & 26.7 & 0.49 \\
\hline & Among treated hypertensive (n) & 22 & 22 & 2 & 2 & 6 & 12 & \\
\hline \multirow[t]{10}{*}{ Women } & Prevalence $(\%)$ & 44.6 & $32.5(28.8-36.2)$ & 20.2 & 35.6 & 55.8 & 75.2 & $<0.001$ \\
\hline & $\begin{array}{l}S B P / D B P \geq 140 / 90 \mathrm{~mm} \mathrm{Hg} \text { or } \\
\text { treatment }(n)\end{array}$ & 447 & 447 & 64 & 73 & 140 & 170 & \\
\hline & Awareness (\%) & 40.5 & 20.9 (15.6-26.2) & 9.3 & 26 & 42.8 & 54.5 & $<0.001$ \\
\hline & Among hypertensives (n) & 181 & 181 & 6 & 19 & 60 & 96 & \\
\hline & Treatment (\%) & 61.3 & $43.3(13.9-72.7)$ & 33.3 & 57.9 & 53.3 & 68.9 & 0.03 \\
\hline & Among aware hypertensives & 111 & 111 & 2 & 11 & 32 & 66 & \\
\hline & Control A (\%) & 28.8 & $8(4.6-13.8)$ & 0 & 18.1 & 21.8 & 34.8 & 0.08 \\
\hline & Among treated hypertensive $(n)$ & 32 & 32 & 0 & 2 & 7 & 23 & \\
\hline & Control B (\%) & 38.7 & $12.8(7.2-18.4)$ & 0 & 2.7 & 31.3 & 45.5 & 0.06 \\
\hline & Among treated hypertensive (n) & 43 & 43 & 0 & 3 & 10 & 30 & \\
\hline
\end{tabular}

Data are percentages with numerators below. Control A, blood pressure below 140/90 mm Hg or 130/80 mm Hg among diabetic patients; Control B, blood pressure below $140 / 90 \mathrm{~mm} \mathrm{Hg}$ among all participants.

*Age standardized according to the 2010 Cameroon national population distribution.

DBP, diastolic blood pressure; NA, not applicable; SBP, systolic blood pressure. 

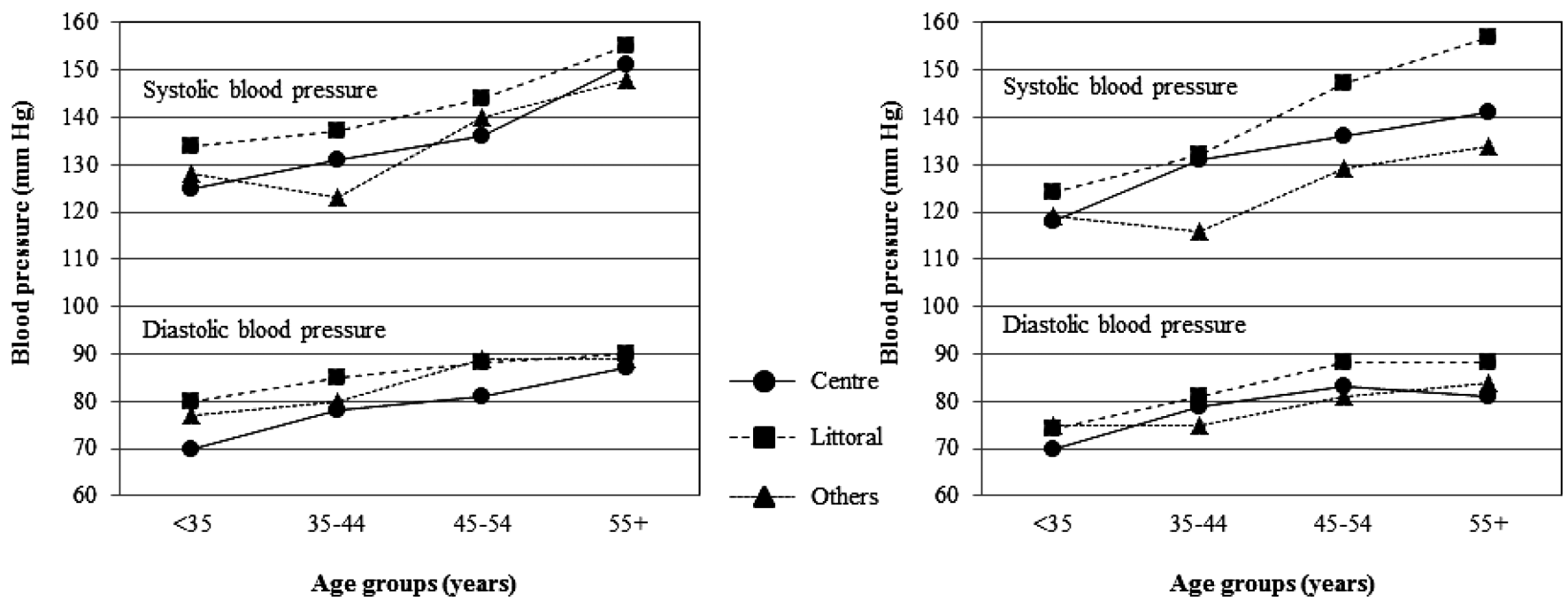

Figure 1 Mean systolic and diastolic blood pressure by age groups for men (left panel) and women (right panel).

Of those aware of their hypertensive status, $57.9 \%$ in men and $61.3 \%$ in women were on BP-lowering medications, similarly across age groups in men $(\mathrm{p}=0.53$ for linear trend), and with a modest linearly increasing trend with age in women $(\mathrm{p}=0.03$, table 2$)$. Among treated patients, $27.5 \%$ in men and $38.7 \%$ in women were at target BP levels (ie, systolic (and diastolic) $\mathrm{BP}<140 \quad(90) \mathrm{mm} \mathrm{Hg}$ ), and similarly across age strata (both $\mathrm{p} \geq 0.06$ for linear trend). Control rate was about $10 \%$ lower when the target BP level of $<130$ (80) was applied to participants with diabetes (table 2).

Crude prevalence of hypertension, awareness and treatment varied significantly across participating regions (all $\mathrm{p}<0.001)$. The highest crude prevalence $(53.6 \%)$ was observed in the Littoral region, while the highest crude awareness $(60.9 \%)$ and treatment rates $(49 \%)$ were observed in provinces other than Centre ad Littoral (table 2). Control rate was also higher in those two regions when the threshold level of $140 / 90 \mathrm{~mm} \mathrm{Hg}$ was applied to all treatment participants $(p<0.001)$. This difference, however, was non-significant when the threshold of $130 / 80 \mathrm{~mm} \mathrm{Hg}$ was applied to participants with diabetes. The age trends in prevalence, awareness, treatment and control across regions were largely similar to those observed in men and women (table 2).

\section{Predictors of hypertension and control among urban dwellers}

Unadjusted and adjusted ORs and 95\% CIs for the association of prevalent hypertension with potential predictors are shown in table 3. In multivariable logistic regression models adjusted for age, sex, parental history of hypertension, BMI and region, the significant predictors of prevalent hypertension were male sex, increasing age, region, parental history of hypertension, personal history of diabetes, high BMI and high waist circumference (table 3). In multivariable models with similar level of adjustment (table 4), male sex, high BMI and physical inactivity were associated with poor control of hypertension, while being from Regions other than Centre or Littoral was associated with good control among treated patients (table 4).

\section{Sensitivity analysis}

Among participants with newly diagnosed hypertension based on the first BP measurement (688 participants), $537(78 \%)$ had a valid second measurement. Their mean BP (SD) was 159.4 (19) for systolic and 94.4 (14.2) $\mathrm{mm} \mathrm{Hg}$ for diastolic based on the first measurement. Equivalents were 154.5 (19) and 93 (13.1) $\mathrm{mm} \mathrm{Hg}$ based on the average of the two measurements. Of the 537 participants, $461(85.8 \%)$ had hypertension (systolic/diastolic $\mathrm{BP} \geq 140 / 90 \mathrm{~mm} \mathrm{Hg}$ ) using the average of the two BP measurements.

\section{DISCUSSION}

In this self-selected urban adult population study from Cameroon, we found a high prevalence of hypertension, coupled with low detection, treatment and control rates. The high prevalence was largely driven by age, as well as by gender and excess weight. However, among those diagnosed and on treatment, control rate was similar across age groups, although there were suggestions of regional differences, possibly reflecting underling differences in the access to healthcare and health resources utilisation. Our study provides comparative data across major cities in Cameroon and suggests findings compatible with previously reported high prevalence rates of hypertension in the country.

\section{Prevalence of hypertension}

During the last 10 years, at least two prevalence studies on hypertension have been reported in urban Cameroon, applying similar definitions for hypertension, but different sampling strategies. ${ }^{79} 18$ The age-adjusted prevalence of hypertension in the current study is 
Table 3 Crude and adjusted ORs for predictors of hypertension among self-selected urban dwellers in Cameroon

\begin{tabular}{|c|c|c|c|c|c|}
\hline Variable & Category & Unadjusted ORs $(95 \% \mathrm{Cl})$ & $\mathbf{p}$ & Adjusted ORs $(95 \% \mathrm{CI})^{*}$ & $\mathbf{p}$ \\
\hline Sex & Men & 1.25 (1.05 to 1.48$)$ & 0.01 & 1.63 (1.34 to 2$)$ & $<0.001$ \\
\hline \multirow[t]{4}{*}{ Age (years) } & $<35$ & 1 (reference) & $<0.001$ & 1 (reference) & $<0.001$ \\
\hline & $35-44$ & $1.74(1.35$ to 2.25$)$ & & $1.32(1.01$ to 1.73$)$ & \\
\hline & $45-54$ & 3.75 (2.93 to 4.81$)$ & & 2.81 (2.16 to 3.64$)$ & \\
\hline & $\geq 55$ & 9.41 (7.12 to 12.43$)$ & & 8.27 (6.19 to 11.04$)$ & \\
\hline \multirow[t]{3}{*}{ Region } & Centre & 1 (reference) & $<0.001$ & 1 (reference) & $<0.001$ \\
\hline & Littoral & 2.11 (1.73 to 2.57$)$ & & 1.89 (1.52 to 2.36$)$ & \\
\hline & Others & 1.80 (1.36 to 2.37$)$ & & 1.38 (1.01 to 1.89$)$ & \\
\hline Parental hypertension & Yes & $1.47(1.21$ to 1.77$)$ & $<0.001$ & $1.55(1.25$ to 1.92$)$ & $<0.001$ \\
\hline Diabetes mellitus & Yes & 3.77 (2.61 to 5.44$)$ & $<0.001$ & $2.63(1.75$ to 3.94$)$ & $<0.001$ \\
\hline Dyslipidemia & Yes & $2(0.67$ to 5.98$)$ & 0.22 & $1.55(0.47$ to 5.11$)$ & 0.47 \\
\hline Gout & Yes & $3.36(1.33$ to 8.49$)$ & 0.01 & $1.70(0.62$ to 4.67$)$ & 0.30 \\
\hline \multirow[t]{3}{*}{ Smoking } & Never & 1 (reference) & 0.11 & 1 (reference) & 0.62 \\
\hline & Former & 1.59 (1.01 to 2.51$)$ & & $0.96(0.59$ to 1.65$)$ & \\
\hline & Current & $0.90(0.63$ to 1.29$)$ & & $0.82(0.54$ to 1.22$)$ & \\
\hline Physical activity & No & $0.90(0.76$ to 1.07$)$ & 0.23 & $1.13(0.93$ to 1.38$)$ & 0.21 \\
\hline Excessive alcohol & Yes & 1.33 (1.06 to 1.66$)$ & 0.01 & $1.05(0.81$ to 1.36$)$ & 0.70 \\
\hline \multirow[t]{3}{*}{ Body mass index } & Normal & 1 (reference) & $<0.001$ & 1 (reference) & $<0.001$ \\
\hline & Overweight & $2.03(1.65$ to 2.50$)$ & & $1.94(1.54$ to 2.45$)$ & \\
\hline & Obese & 3.54 (2.83 to 4.43$)$ & & 3.32 (2.57 to 4.29$)$ & \\
\hline High waist girth & & 2.12 (1.78 to 2.52$)$ & $<0.001$ & 1.94 (1.51 to 2.48$)$ & $<0.001$ \\
\hline
\end{tabular}

higher than that reported by Kamadjeu $^{9}$ in 2003, but similar to the findings of Fezeu ${ }^{7}$ around that same time. This balance of findings would tend to suggest that the prevalence of hypertension in this setting is either stabilising or growing at a much slower pace than previously reported. $^{7}$
Elsewhere, available data on hypertension in Africa are from very heterogeneous studies, and therefore offer less opportunities for reliable comparison. ${ }^{3}$ Such heterogeneities include differences in sampling methods and study settings (predominance of hospital-based study), the type of participants enrolled, the measurements of

Table 4 Crude and adjusted ORs for predictors of hypertension control among self-selected and treated hypertensives in four main cities of Cameroon

\begin{tabular}{|c|c|c|c|c|c|}
\hline Variable & Category (\%) & Unadjusted ORs (95\% Cl) & $\mathbf{p}$ & Adjusted ORs $(95 \% \mathrm{Cl})^{*}$ & $\mathbf{p}$ \\
\hline Sex & Men & $059(0.35$ to 1$)$ & 0.05 & $0.47(0.26$ to 0.86$)$ & 0.01 \\
\hline \multirow[t]{4}{*}{ Age (years) } & $<35$ & 1 (reference) & 0.87 & 1 (reference) & 0.63 \\
\hline & $35-44$ & $0.54(0.12$ to 2.32$)$ & & $0.38(0.07$ to 1.99$)$ & \\
\hline & $45-54$ & $0.68(0.19$ to 2.45$)$ & & 0.57 (0.13 to 2.41$)$ & \\
\hline & $\geq 55$ & $0.67(0.19$ to 2.34$)$ & & $0.46(0.11$ to 1.88$)$ & \\
\hline \multirow[t]{3}{*}{ Region } & Centre & 1 (reference) & $<0.001$ & 1 (reference) & $<0.001$ \\
\hline & Littoral & $0.72(0.35$ to 1.50$)$ & & $0.70(0.33$ to 1.52$)$ & \\
\hline & Others & 3.36 (1.64 to 6.87$)$ & & 3.50 (1.65 to 7.42$)$ & \\
\hline Parental hypertension & Yes & $1.44(0.87$ to 2.40$)$ & 0.16 & $1.56(0.89$ to 2.75$)$ & \\
\hline Diabetes mellitus & Yes & $2.73(1.60$ to 4.67$)$ & $<0.001$ & $1.83(0.98$ to 3.39$)$ & 0.06 \\
\hline Dyslipidemia & Yes & $0.74(0.08$ to 6.75$)$ & 0.79 & $1.30(0.13$ to 13.26$)$ & 0.83 \\
\hline Gout & Yes & NA (none) & & & \\
\hline \multirow[t]{3}{*}{ Smoking } & Never & 1 (reference) & 0.53 & 1 (reference) & 0.72 \\
\hline & Former & $0.79(0.21$ to 2.89$)$ & & $1.26(0.30$ to 5.34$)$ & \\
\hline & Current & 0.32 (0.04 to 2.57$)$ & & 0.44 (0.05 to 3.97$)$ & \\
\hline Physical activity & No & $0.30(0.17$ to 0.56$)$ & $<0.001$ & $0.36(0.20$ to 0.66$)$ & 0.001 \\
\hline Excessive alcohol & Yes & 0.59 (0.26 to 1.32$)$ & 0.20 & $0.64(0.26$ to 1.60$)$ & 0.34 \\
\hline \multirow[t]{3}{*}{ Body mass index } & Normal & 1 (reference) & 0.002 & 1 (reference) & 0.003 \\
\hline & Overweight & 0.41 (0.22 to 0.77$)$ & & $0.44(0.22$ to 90$)$ & \\
\hline & Obese & $0.34(0.18$ to 0.66$)$ & & 0.28 (0.14 to 0.59$)$ & \\
\hline High waist girth & & $0.86(0.51$ to 1.44$)$ & 0.56 & 0.77 (0.33 to 1.77$)$ & 0.54 \\
\hline
\end{tabular}


$\mathrm{BP}$ and definition of hypertension and the time period when the study was conducted. ${ }^{19}$ Reliable, large-scale, population-based data on high BP in SSA are very limited; however, available recent studies provide findings that demonstrate similarly high prevalence of hypertension in urban settings. ${ }^{20-22}$ Moreover, those findings already tend to be similar to those reported in the developed world, ${ }^{23}{ }^{24}$ therefore, raising serious concerns given the young age of clinical onset of hypertension in Africa.

\section{Awareness, treatment and control of hypertension}

In Cameroon, over the last 10 years, there have been a number of initiatives aimed at scaling up the fight against chronic diseases in general, and hypertension and diabetes mellitus in particular, ${ }^{25}$ including: (1) the adoption of a National Strategy for hypertension and diabetes $^{25}$ and (2) the development of training and taskshifting programmes to improve detection and management at the primary care level. ${ }^{13}{ }^{26}$ Findings from our study would tend to suggest that the good will contained in the National Strategy has perhaps not yet been fully translated into actions with sizable positive effects on the health of the population. For instance, the strategy aimed to improve the level of risk factors by $25 \%$ and achieve optimal control among those diagnosed with the condition. ${ }^{25}$ However, we found awareness, treatment and control rates that were within the range of those previously reported in Cameroon prior to the adoption of the strategy ${ }^{7} 9$ and recently in other settings in Africa. ${ }^{20} 2225$ The low awareness rate, if confirmed, could be blamed on low-detection activity and accordingly non-optimal performance of the National strategy. It is also possible that many participants already diagnosed with hypertension, and perhaps on treatment and controlled on such treatment, did not feel the need to attend the screening campaign again. This would have the undesirable effect of biasing our estimates by providing much lower than the true figures. It is also possible that those with known and treated condition instead turned out in higher number to use the campaign as an opportunity for their health check-up free of charge. Our stratified analyses suggest that this mix could vary substantially by participating centres. In general, however, low awareness of hypertension has been reported as a global phenomenon, ${ }^{27}$ although the magnitude may be less important in the developed world. ${ }^{23}{ }^{28}$ In the USA, for instance, awareness of hypertension is as high as $76 \%,{ }^{28}$ reflecting the success achieved by a coordinated policy to detect individuals with higher-than-optimal BP levels.

The low treatment and control rates in our study reflect the interplay between many factors that were not directly captured by the current study. These include patient-level, healthcare provider level and health system-level factors. Indeed, patients are expected to be treated and controlled only if they can access appropriate health services, receive adequate advice and prescriptions and subsequently afford and adhere to those prescriptions. Accessibility to healthcare facility has likely improved in urban settings in Cameroon in recent years. However, the physician-to-population ratio, just like in many other countries in the region, is still very $l w^{29}$ and may explain the low awareness and treatment gaps. Affordability of the cost of care also remains a major barrier in the study setting where out-of-pocket spending is the main source of funding for healthcare costs. Adherence to prescribed medications is another patient-level determinant of risk factor control not investigated in the present study. Studies in Africa have shown that non-adherence to treatment and follow-up for hypertension was very common. ${ }^{30-32}$ In one intervention study in Cameroon, for instance, just about half of the participants were still in the programme at 1-year follow-up. ${ }^{3}$

\section{Potential limitations and strengths of our study}

The present study has some limitations. Participants were self-selected and may therefore not necessarily be representative of the general population in participating cities. Access to mass media (radio and television) is almost universal in major cities in the countries, and there is therefore no suggestion that advertisement of the campaign would have selectively reached certain portions of the population. It remains, however, that participants in the study could still differ from the general population by being more or less health conscious, and having less severe disease, for example, which could affect some parameters in the study. The study used a cross-sectional design, which precludes any causality inference. Diagnosis of hypertension was based on BP measurements during a single encounter, which is at variant with guidelines recommendations for hypertension diagnosis using two measurements recorded on three separate occasions. ${ }^{17}$ This may have overestimated the prevalence of hypertension and underestimated the level of BP control. This, however, would not affect comparisons with previous epidemiological studies that have used similar measurement methodology. Diagnosis of hypertension among those with no history of hypertension in our study was based on a single BP measurement. Our sensitivity analysis suggests that this approach could inflate the crude prevalence by about $5.4 \%$ and $4.6 \%$ among those not known to have hypertension prior to the survey and at the total population level, respectively. Nevertheless, even after accounting for this possible effect, our estimates would still be within sampling variation of the figures previously reported in this setting. It is also of note that no participant received a definitive diagnosis of hypertension as a result of taking part in this study. Those with elevated BP levels were instead referred to healthcare facilities for further evaluation. The strengths of this study include the large sample of the general population and the rigorous collection of various lifestyle factors, medical data and BP measurements by trained staff according to standardised 
protocols, the adequate standardisation of prevalence and allowing comparisons with other African countries. In addition, our sampling approach provides evidence that simple announcements through mass media can attract from the community a large number of individual at risk of undiagnosed hypertension.

\section{Conclusions}

In conclusion, our study has provided findings that are in line with the high prevalence of hypertension previously reported in urban settings in Africa. The study also suggests that efforts to detect and treat to the targets those with the disease are still below optimal. This raises serious concerns about the prospects of having to care very soon for both patients with higher-than-optimal BP and many more with target organ lesions subsequent to longstanding hypertension. There are already some indications that the burden of stroke, end-stage renal disease and heart failure related to hypertension is growing in the country and the region. ${ }^{2} 633$

\section{PERSPECTIVES}

The low awareness, treatment and control rates of hypertension in this potentially health conscious urban sub-Saharan population invite innovative approaches to improve prevention, detection, treatment of hypertension beyond the traditional healthcare facilities-based approaches that are currently in force in many countries in the region.

\author{
Author affiliations \\ ${ }^{1}$ Department of Internal Medicine, Douala General Hospital, Douala, Cameroon \\ ${ }^{2}$ Department of Internal Medicine, Faculty of Health Sciences, University \\ of Buea, Buea, Cameroon \\ ${ }^{3}$ NCRP or Cardiovascular and Metabolic Disease, South African Medical \\ Research Council \& University of Cape Town, Cape Town, South Africa \\ ${ }^{4}$ Department of Internal Medicine, Faculty of Medicine and Biomedical \\ Sciences, Yaounde, Cameroon \\ ${ }^{5}$ Department of Internal Medicine, Yaounde General Hospital,Douala, \\ Cameroon \\ ${ }^{6}$ Department of Internal Medicine, Bafoussam Regional Hospital, Douala, \\ Cameroon \\ ${ }^{7}$ Department of Internal Medicine, Bamenda Military Hospital, North West \\ Region, Cameroon \\ ${ }^{8}$ Department of Internal Medicine, Yaounde University Teaching Hospital, \\ Yaounde, Cameroon \\ Author footnote \\ Members list in the appendix section.
}

Acknowledgements The authors would like to express their gratitude to the following bodies and individuals for their contribution to the success of this study: (1) The Cameroon Ministry of public health for providing the blood pressure devices and health staff; (2) The executive committee and members of the Cameroon Cardiac Society for their support for data collection; (3) Servier Pharma Cameroon for a financial contribution to support data processing and drafting of the manuscript; (4) All specialist physicians, enthusiastic general practitioners, medical students and nurses involved in data collection and (5) All those who helped at different stages of the project and the fellow Cameroonians who volunteered across the four participating cities to take part in the study.

Contributors AD and APK had full access to all of the data in the study and takes responsibility for the integrity of the data and the accuracy of the data analysis. Study concept and design by AD, APK, WFTM, KBN and SK. Acquisition of data by HB, AM, CKK, JA, YM, CB, PM, FK, AD, JN, CO, HL. Analysis and interpretation by $A D, A P K$ and WFTM. Drafting of the manuscript by AD, APK and WFTM. Critical revision of the manuscript for important intellectual content by all coauthors.

Competing interest None.

Ethics approval Cameroon National Ethics Committee.

Provenance and peer review Not commissioned; externally peer reviewed.

Data sharing statement No additional data available.

\section{REFERENCES}

1. Kearney PM, Whelton M, Reynolds K, et al. Global burden of hypertension: analysis of worldwide data. Lancet 2005;365:217-23.

2. Kengne AP, Anderson CS. The neglected burden of stroke in sub-Saharan Africa. Int J Stroke 2006:1:180-90.

3. Addo J, Smeeth L, Leon DA. Hypertension in sub-Saharan Africa: a systematic review. Hypertension 2007;50:1012-18.

4. Kengne AP, Amoah AG, Mbanya JC. Cardiovascular complications of diabetes mellitus in sub-Saharan Africa. Circulation 2005;112:3592-601.

5. Damasceno A, Cotter G, Dzudie A, et al. Heart failure in sub-Saharan Africa: time for action. J Am Coll Cardiol 2007;50:1688-93.

6. Kengne AP, Awah PK. Classical cardiovascular risk factors and all-cause mortality in rural Cameroon. QJM 2009;102:209-15.

7. Fezeu L, Kengne AP, Balkau B, et al. Ten-year change in blood pressure levels and prevalence of hypertension in urban and rural Cameroon. J Epidemiol Community Health 2010;64:360-5.

8. Turnbull F. Effects of different blood-pressure-lowering regimens on major cardiovascular events: results of prospectively-designed overviews of randomised trials. Lancet 2003;362:1527-35.

9. Kamadjeu RM, Edwards R, Atanga JS, et al. Prevalence, awareness and management of hypertension in Cameroon: findings of the 2003 Cameroon Burden of Diabetes Baseline Survey. J Hum Hypertens 2006;20:91-2.

10. Leon DA. Cities, urbanization and health. Int J Epidemiol 2008;37:4-8.

11. Popkin BM. Global nutrition dynamics: the world is shifting rapidly toward a diet linked with noncommunicable diseases. Am J Clin Nutr 2006;84:289-98.

12. de-Graft Aikins A, Unwin N, Agyemang C, et al. Tackling Africa"s chronic disease burden: from the local to the global. Glob Health 2010;6:5.

13. Lekoubou A, Awah P, Fezeu L, et al. Hypertension, diabetes mellitus and task shifting in their management in sub-Saharan Africa. Int $J$ Environ Res Public Health 2010;7:353-63.

14. Cameroon's National Institute of Statistics. Statistical year book 2010. Chapter 4: Characteristics of the population 2011:39-52. Available at www.statistics-cameroon.org/downloads/annuaire2010/ chap4.pdf. Accessed on 11/12/2011.

15. Cameroon's National Institute of Statistics. Population du Cameroun en 2010. 2011. Available at www.statistics-cameroon.org/ downloads/La_population_du_Cameroun_2010.pdf. Accessed on $15 / 11 / 2011$

16. Woodward M, ed. Epidemiology: study design and data analysis. 2nd edn. New York: Chapman \& Hall/CRC, 2005.

17. Mancia G, De Backer G, Dominiczak A, et al. 2007 Guidelines for the management of arterial hypertension: the Task Force for the Management of Arterial Hypertension of the European Society of Hypertension (ESH) and of the European Society of Cardiology (ESC). J Hypertens 2007;25:1105-87.

18. Kengne AP, Awah KP, Fezeu L, et al. The burden of high blood pressure and related risk factors in urban sub-Saharan Africa: evidences from Douala in Cameroon. Afr Health Sci 2007;7:38-44.

19. Danaei G, Finucane MM, Lin JK, et al. National, regional, and global trends in systolic blood pressure since 1980: systematic analysis of health examination surveys and epidemiological studies with 786 country-years and 5.4 million participants. Lancet 2011;377:568-77.

20. Jenson A, Omar AL, Omar MA, et al. Assessment of hypertension control in a district of Mombasa, Kenya. Glob Public Health 2011;6:293-306.

21. Ulasi II, ljoma CK, Onodugo OD. A community-based study of hypertension and cardio-metabolic syndrome in semi-urban and rural communities in Nigeria. BMC Health Serv Res 2010;10:71.

22. Damasceno A, Azevedo A, Silva-Matos C, et al. Hypertension prevalence, awareness, treatment, and control in mozambique: 
urban/rural gap during epidemiological transition. Hypertension 2009;54:77-83.

23. Wagner A, Sadoun A, Dallongeville J, et al. High blood pressure prevalence and control in a middle-aged French population and their associated factors: the MONA LISA study. $J$ Hypertens 2011;29:43-50.

24. Wolf-Maier K, Cooper RS, Banegas JR, et al. Hypertension prevalence and blood pressure levels in 6 European countries, Canada, and the United States. JAMA 2003;289:2363-9.

25. Njamnshi AK, Bella Hiag A, Mbanya JC. From research to policy: the development of a national diabetes programme in Cameroon. Diabetes Voice 2006;55:18-21.

26. Kengne AP, Sobngwi E, Fezeu L, et al. Setting-up nurse-led pilot clinics for the management of non-communicable diseases at primary health care level in resource-limited settings of Africa. PAMJ 2009;3:10.

27. Marques-Vidal P, Tuomilehto J. Hypertension awareness, treatment and control in the community: is the 'rule of halves' still valid? J Hum Hypertens 1997;11:213-20.

28. Cheung BM, Ong KL, Man YB, et al. Prevalence, awareness, treatment, and control of hypertension: United States National Health and Nutrition Examination Survey 2001-2002. J Clin Hypertens (Greenwich) 2006;8:93-8.

29. World Health Organisation. Task shifting to tackle health worker shortage, WHO, Geneva, 2007.

30. Kengne AP, Awah PK, Fezeu LL, et al. Primary health care for hypertension by nurses in rural and urban sub-Saharan Africa. J Clin Hypertens (Greenwich) 2009;11:564-72.
31. Labhardt ND, Balo JR, Ndam M, et al. Improved retention rates with low-cost interventions in hypertension and diabetes management in a rural African environment of nurse-led care: a cluster-randomised trial. Trop Med Int Health 2011. doi: 10.1111/j.13653156.2011.02827.x. [Epub ahead of print]

32. Dennison CR, Peer N, Steyn K, et al. Determinants of hypertension care and control among peri-urban Black South Africans: the $\mathrm{HiHi}$ study. Ethn Dis 2007;17:484-91.

33. Halle MP, Kengne AP, Ashuntantang G. Referral of patients with kidney impairment for specialist care in a developing country of sub-Saharan Africa. Ren Fail 2009;31:341-8.

\section{APPENDIX 1}

\section{Cameroon Cardiac Society (CCS) investigators group}

1. Douala: Anastase Dzudie, Hamadou Ba, Henri Roger Ngote Christian Biholong, Félicité Kamdem, Armel Djomou, Jules Njebet, Cyrille Wambo, Roger Mboulley Kotto, Barbara Bouellet Abeng, Marielle Epacka Ewane Lobe and Yves Monkam.

2. Yaounde: Alain Menanga, Pierre Mintom, Euloge Yiagnigni, Mérimée Ouankou, Christophe Nouedoui, Pierre Ndobo, Marie Ntep, Monique Kenfack, Sylvie Ndongo, Martine Tchuem, Edvine Wawo, Walinjom F.T. Muna, Kathleen Ngu Blackett and Samuel Kingue.

3. Bafoussam: Charles Kouam Kouam

4. Bamenda: Joseph Abah. 